\title{
Evaluasi Implementasi Program Bantuan Operasional Sekolah (Bos) Di Smk Ypk Kesatuan Jakarta
}

\author{
Masruroh, Somariah Fitriani \\ Universitas Muhammadiyah Prof.Dr.HAMKA, Jl. Warung \\ Buncit Raya no 17Mampang, Jakarta Selatan \\ rurohrosyadi@yahoo.com
}

Received: 04 Januari 2021; Revised: 26 Februari 2021; Accepted: 28 April 2021

DOI: http://dx.doi.org/10.37905/aksara.7.2.551-562.2021

\begin{abstract}
Abstrak.
Penelitian ini bertujuan untuk mengetahui dan menganalisa hambatan- hambatan dalam sosialisasi program BOS, implementasi program BOS dan manajemen pengelolaan program BOS di SMK YPK Kesatuan Jakarta, dengan menggunakan modelevaluasi kesenjangan (Discrepancy Model Evaluation). Pengumpulan data dilakukan dengan menggunakan observasi, wawancara terstruktur, dan dokumentasi. Wawancara dilakukan dengan kepala Sekolah, bendahara BOS, guru, orang tua dan peserta didik.

Hasil penelitian menunjukkan ada kesenjangan dalam sosialisasi program BOS dan hambatan-hambatanya yaitu komunikasi yang kurang efektif , TIM BOS tidak memahami tugas dan fungsinya. Implementasi program BOS di SMK YPK Kesatuan Jakarta, 10 komponen sesuai juknis, 3 komponen terjadi ketimpangan antara juknis BOS dengan realisasi pembelanjaan yaitu pembelian alat multimedia pembelajaran, pembayaran honor guru, dan kegiatan praktek kerja industri. Manajemen pengelolaan dana BOS di SMK YPK Kesatuan Jakarta terjadi ketimpangan, peneliti tidak mendapatkan dokumen RKAS untuk dianalisis.
\end{abstract}

Kata Kunci: Manajemen keuangan, program BOS, transparansi, akuntabiliti

\section{Abstract.}

This study aims to identify and analyze the obstacles in the socialization of BOS program, the implementation of the BOS program and the management of the BOS program at SMK YPK Kesatuan Jakarta, using the Discrepancy Model Evaluation. Data collection was carried out using observation, structured interviews, and documentation. Interviews were conducted with school principals, BOS treasurers, teachers, parents and students.

The results showed that there were gaps in the socialization of the BOS program and its obstacles were ineffective communication, the BOS TEAM did not understand its duties and functions. The implementation of the BOS program at SMK YPK Kesatuan Jakarta, 10 components according to technical guidelines, 3 components there is an imbalance between the BOS technical guidelines and the realization of spending, namely thepurchase of multimedia learning tools, payment of teacher salaries, and industrial workpractice activities. Inequality in 


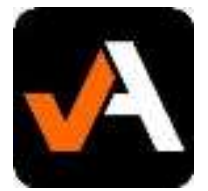

AKSARA: Jurnal Ilmu Pendidikan Nonformal

P-ISSN 2407-8018 E-ISSN 2721-7310 DOI prefix $\underline{10.37905}$

Volume 07 (02) Mei 2021

http://ejurnal.pps.ungac.id/index.php/Aksara

the management of BOS funds at SMK YPK Kesatuan Jakarta, researchers did not get RKAS documents for analysis.

Key words: financial management, BOS program, transparency, accountability

\section{PENDAHULUAN}

Beberapa isu yang menyita perhatian banyak kalangan di Indonesia adalah dana alokasi pendidikan dari APBN dan APBD yang telah ada dalam undangundang No.48 tahun 2008. Alokasi dana $20 \%$ tersebut untuk pendidikan sampai saat ini masih terus diperjuangkan. Hal ini meliputi subsidi pendidikan baik berbentuk Bantuan Operasional Sekolah (BOS) atau yang lainnya, dan peningkatan kesejahteraan guru. Teori pembiayaan pendidikan ini sering kali bertolak belakang dengan praktek kebijakanyang diterapkan di Indonesia. Setelah dikaji dengan pendekatan makro pembiayaan pendidikan ini sangat tidak sesuai dan jauh dari kata ideal dalam dunia pendidikan. Namun kesenjangan sosial ini bisa dilakukan oleh para manajemen yang sudah kompeten dalam mengelola keuangan disektor pendidikan yang ada di Negara ini(Halik, Hidayati and Amin, 2018).

Bantuan Operasional Sekolah (BOS) SMK adalah program Pemerintah berupa pemberian dana langsung ke SMK baik Negeri maupun Swasta untuk membantu biaya operasional sekolah non personalia. Program tersebut disalurkan kepada SMK dalam bentuk uang sebesar Rp 1.600.000 per siswa setiap tahunnya yang bertujuan untuk 1) mewujudkan pelaku pendidikan sekolah menengah kejuruan yang kuat; (2) Mewujudkan akses sekolah menengah kejuruan yang meluas, merata, dan berkeadilan; dan (3) Mewujudkan pembelajaran yang bermutu. Dengan adanya program BOS yang meluaskan aksesnya hingga jenjang pendidikan menengah diharapkan banyak anak- anak Indonesia dengan usia sekolah akan dapat melanjutkan pendidikannya hingga ke jenjang pendidikan menengah dan tidak ada siswa yang putus sekolah (drop out) serta kualitas pendidikan diharapkan dapat meningkat pada tahun - tahun kedepannya (Sunardi, 2017). Hasil penelitian mengidentifikasikan bahwa dana BOS dapat meningkatkan performa peserta didik (Sulistyaningrum, 2016). Di Negara maju, seperti Negara Inggris, bantuan dana yang diberikan pemerintahnya memberikan dampak yang positif dan signifikan terhadap partisipasi anak anak ke sekolah (Dearden et al., 2005). Begitu juga dana yang diberikan untuk anak anak yang berasal dari keluarga miskin di Australia meningkatkan partisipasi mereka untuk bersekolah sebesar tiga persen (Dearden and Heath, 1996). Di Negara berkembangpun seperti Meksiko, Ekoador, Colombia, Honduras dan Nikaragua menemukan bahwa ada perbedaan yang signifikan dalam pendaftaran sekolah dimana terjadi peningkatan pendaftaran dan pengurangan putus sekolah karena adanya pemberian dana langsung kepada anak anak (Glewwe and Olinto, 2004; Schultz, 2004; Attanasio, Fitzsimons and Gomez, 2005; Maluccio and Flores, 2005; Schady and Araujo, 2008).

Keberhasilan program BOS dipengaruhi oleh faktor pengelolaan dana dan segala sumber daya yang ada dalam program BOS. Pengelolaan Dana BOS SMK yang baik akan mampu membantu ketercapaian tujuan dari program BOS SMK dengan efektif danefisien. Sekolah menempati posisi penting dalam penentuan 
penggunaan Dana BOS SMK, karena sekolah merupakan instansi yang terkait langsung pengelolaan dana BOS. Kesalahan oleh pengelolaan dapat menimbulkan hambatan dalam pelaksanaan Pengelolaan Dana BOS SMK. Kurang spesifiknya petunjuk yang ada dalam petunjuk teknis BOS SMK menimbulkan penerjemahan yang berbeda-beda oleh pihak Pengelolaan Dana BOS SMK. Hal ini menjadi permasalahan dan dapat menimbulkan dugaan penyelewengan. Berdasarkan temuan Badan Pemeriksa Keuangan (BPK) 2018 dan temuan Jaringan Pemantau Pendidikan Indonesia (JPPI) 2019, ada beberapa penyimpangan berupa penggelapan dana BOS yang dilakukan baik dari tingkat SD hingga SMA/SMK dibanyak daerah secara umum masih buruk (Oebadillah, 2019).

BPK Republik Indonesia menemukan adanya tujuh sekolah di Kota Serang yang menggunakan dana BOS tidak sesuai peruntukannya sebesar Rp 108.278.000, setelah dilakukan pemeriksaan dokumen dan uji petik terhadap dokumen pertanggung jawaban dan cek fisik pada tujuh sekolah tersebut. BPK menilai hal tersebut disebabkan karena kepala sekolah belum optimal dalam menggunakan dana BOS , pengawasan dan lemahnya pengendalian oleh tim manajemen BOS Kota Serang (Tim Pikiran Rakyat, 2019). Maka dari itu pentingnya pengelolaan dana BOS dilakukan secara transparan dan akuntabel artinya dalam pengelolaan dana BOS, sekolah dapat mempertanggungjawabkan penggunaan dana BOS terhadap masyarakat. Pentingnya transparansi dan akuntabilitas penggunaan dana BOS kepada publik merupakan salah satu wujud kontrol masyarakat dimana masyarakat merupakan komponen yang berperan penting dalam penyelenggaraan pendidikan. Sekolah dapat menginformasikan secara tertulis rekapitulasi penerimaan dan penggunaan dana BOS kepada orang tua siswa setiap semester bersamaan denganpertemuan orang tua siswa dan sekolah pada saat penerimaan raport. Melihat pentingnya pengelolaan dana BOS dalam penyelenggaraan pendidikan dan berbagai masalah yang melingkupinya, penelitian ini masih memiliki daya tarik tersendiri dan perlu diteliti lebih mendalam.

Beberapa hasil penelitian sebelumnya yang dilakukan di berbagai daerah danwilayah di Indonesia menunjukkan bahwa implementasi penyaluran dana Bantuan operasional sekolah (BOS) belum berjalan secara maksimal dikarenakan berbagai keterbatasan dan hambatan. Hasil penelitian menunjukkan bahwa ada tiga aspek yang belum terlaksana dengan baik dalam pelaksanaan penyaluran dana BOS yaitu aspek komunikasi, aspek disposisi dan aspek struktur birokrasi (Anas, 2016). Penelitian yang lain juga menunjukkan bahwa perencanaan, pengalokasian, dan penggunaan dana BOS tidak sesuai Juknis BOS dan pelaporan dana BOS tidak dilakukan secara transparan (Silele, Sabijono and Pusung, 2017). Eka Anggraini dan Mayarn juga melakukan penelitian tentang Evaluasi Program BOS terhadap peningkatan sarana dan prasarana Sekolah Dasar di Kecamatan Tampan Kota Pekanbaru dinyatakan kurang berhasil dengan baik karena kurangnya koordinasi Sekolah dan Komite Sekolah dalam penggunaan dana, tranparansi dan pengawasan (Anggraini, 2013).

Dengan demikian perlu diadakan penelitian berkelanjutan karena dana BOS yang harus diimplementasikan, dikelola dan dipertanggungjawabkan 
sekolah, kemudian melihat sejauh mana dana BOS sebagai amanah UUD 1945, Sisdiknas 2003 dan Permendiknas tahun 2012 No. 46, yang disalurkan oleh pemerintah dapat berdaya hasil dan berdaya guna menunjang kualitas pelayanan pendidikan di SMK YPK Kesatuan Jakarta Selatan . Oleh karena itu, perlu penelitian evaluasi program implementasi dana operasional sekolah harus ditunjang dengan kinerja pelayanan yang optimal. Hal ini diperkuat oleh Robbins dan Timothy yang menyatakan bahwa: A number of objectives are addressed by the performance evaluation. One is to help the management decide on advancement, transfers and terminations for general human resources. Training and growth requirements are also defined in the assessments. The knowledge and abilities for workers to develop corrective programs. Finally, they provide workers with input on the company's success and also form the basis for incentives, including wage increases. As we are involved in organisation, we emphasize performance appraisal as a method for the input and distribution of awards (Robbin, 2013).

Menurut Nawawi "Evaluasi kinerja diartikan juga sebagai kegiatan mengukur/menilai pelaksanaan pekerjaan untuk menetapkan sukses atau gagalnya seorang pekerja dalam melaksanakan tugas dan tanggung jawab dibidang kerjanyamasing-masing" (Prihatin, 2013). Dengan demikian, evaluasi merupakan suatu hal yang sangat penting dalam suatu proses pekerjaan, karena dengan adanya evaluasi maka hal tersebut akan mempermudah jalannya suatu proses kerja dalam sebuah organisasi.

Realitanya di SMK YPK Kesatuan Jakarta implementasi program dana BOSmenunjukkan bahwa masih ada ketidak- maksimalan dalam hal pelaksanaan program, sehingga evaluasi mengenai program dana BOS perlu untuk dilakukan secara berkelanjutan. Dengan demikian tujuan penelitian ini adalah untuk mengevaluasi implementasi program dana BOS tersebut dan mengkaji sejauh mana manajemen pengelolaan dana BOS tersebut mampu mengatasi hambatan hambatan yang terjadi dalam pelaksanaan program dana BOS dan manajemen pengelolaan dan BOS di SMK YPK Kesatuan Jakarta sebagai unit analisa penelitian.

\section{METODE PENELITIAN}

Metode yang digunakan dalam penelitian evaluasi ini adalah metode evaluasi dengan model evaluasi ketimpangan (Discrepancy Evaluation Model, $D E M)$ yang merupakan pendekatan kualitatif deskritif. Adapun penelitian evaluasi ini terkait dengan proses pengumpulan, menganalisis sampai menafsirkan informasi yang didapat dari berbagai sumber dan dilakukan secara sistematis, terencana, dan terukur dalam suatu kegiatan yang kemudian hasil evaluasi akan dijadikan sebagai dasar pertimbangan untukmenentukan alternatif selanjutnya yang akan diambil, sehingga keputusan tersebut benar-benar tepat dan dapat dipertanggungjawabkan. Pemilihan metode kualitatif ini dipergunakan untuk membandingkan antara implementasi dengan kriteria yang telah ditetapkan dan memusatkan perhatian pada masalah-masalah aktual dan fakta-faktayang terjadi pada saat pelaksanaan penelitian. Metode evaluasi dengan kualitatif bertujuan agar peneliti mampu menginterpretasikan ada tidaknya kesenjangan 
antara kenyataan dengan kriteria yang telah ditetapkan.

Penelitian dilakukan di SMK YPK Kesatuan yang terletak di Jakarta selatan ini bertujuan untuk mendeskripsikan atau menjelaskan implementasi program dana BOS khususnya berkaitan dengan kesesuaian antara implementasi yang dilakukan dan peraturan atau ketentuan yang telah ditetapkan. Implementasi yang menjadi fokus penelitian ini terdiri dari 1) hambatan-hambatan dalam sosialisasi program BOS; 2) Implementasi program BOS yang berkaitan dengan alokasi anggaran; dan 3) Manajemen pengelolaan dana BOS yang berkaitan dengan pembuatan RKS dan RKAS. Pengumpulan data dilakukan dengan menggunakan observasi, wawancara dan studi dokumentasi. Wawancara terstruktur dilakukan dengan kepala Sekolah, bendaharaBOS, beberapa guru, orang tua peserta didik dan peserta didik untuk mendapatkan gambaran menyeluruh dan data yang lebih komprehensif mengenai implementasi dana BOS ini. Sedangkan untuk analisa data, penelitian ini menggunakan model Miles and Hubberman yang meliputi tiga alur yaitu reduksi data, penyajian data, dan penarikan kesimpulan.

\section{HASIL DAN PEMBAHASAN}

\section{Hambatan Hambatan dalam sosialisasi program BOS}

Sosialisasi sebuah program merupakan kata kunci untuk mewujudkan sinkronisasi dan harmonisasi pelaksanaan program dalam pencapaian tujuan. Melalui sosialisasi ini diharapkan penyebaran informasi tentang program BOS kepada masyarakat/warga sekolah dapat berjalan dengan baik sehingga warga sekolah maupun masyarakat dapat memahami konsep, prinsip, prosedur dan tahapan pelaksanaan program Dana BOS di SMK YPK Kesatuan Jakarta selaku organisasi pelaksana BOS kurang baik dalam menjalankan sosialisasi program BOS kepada warga sekolah maupun masyarakat.

Beberapa hambatan-hambatan dalam sosialisasi program BOS di SMK YPK Kesatuan Jakarta adalah tidak ada komunikasi yang baik antara kepala sekolah dengan yayasan, kepala sekolah dengan guru, orang tua dan peserta didik. TIM BOS sekolah tidak memahami pentingnya sosialisasi program BOS yang harus dilaksanakan sekolah terhadap guru, orang tua dan peserta didik. TIM BOS sekolah bersikap antipati karena mereka merasa selama ini tidak dilibatkan dalam program BOS. Hal ini mengidentifikasikan bahwa petugas BOS di sekolah kurang serius dalam melaksanakan sosialisasi BOS sehingga peserta didik tidak mendapat informasi yang lengkap tentang dana BOS. Kondisi ini yang merupakan salah satu faktor yang membuat banyak masyarakat terutama orangtua yang anaknya akan masuk Sekolah menengah kejuruan tidak mengetahui BOS dengan jelas. Sementara dalam permendikbud No 3 tahun 2019 tentang tugas dan tanggung jawab Tim Bos adalah melakukan sosialisasi program BOS kepada sekolah-sekolah penerima dana BOS.

Jika dikaitkan dengan penelitian Anas, beliau menyebutkan bahwa faktor utama yang dapat mempengaruhi sosialisasi program BOS Sebagaimana dalam teori Edwar III menyebutkan dipengaruhi oleh empat unsur, yakni: (1) Komunikasi, (2) Sumber Daya,

(3) disposisi, dan (4) Struktur Birokrasi. Keempat Keempat variabel ini saling berhubungan satu sama lainnya (Anas, 2016). Artinya dalam melaksanakan 
sosialisasi program sekolah pasti akan menemukan hambatan-hambatan, dan Tim BOS sekolah harus benar-benar memahami betul juknis BOS yang di dalamnya mengatur tentang tugas yang harus dilakukan oleh Tim BOS sekolah. Di SMK YPK Kesatuan jakarta masih ada hambatan-hambatan dalam melakukan sosialisasi program BOS, sosialisasi hanya dilakukan kepada guru-guru itupun dilakukan secara spontanitas tidak terjadwal dan terprogram dengan baik, sementara sosialisasi terhadap orang tua dan peserta didik belum terlaksana dengan baik karena tidak terjalinnya komunikasi yang baik. Tim BOS sekolah tidak memahmi isi Juknis BOS dengan benar sehingga tidak mengetahui apa yang harus dilakukan oleh Tim BOS sekolah dan SK Tim BOS sekolah hanya sebatas pelengkap administrasi dalam pelaporan SPJ BOS, padahal sosialisasi menjadi tanggung jawab Tim BOS dan merupakan bagian yang sangat penting.

\section{Implementasi program BOS yang berkaitan dengan alokasi anggaran}

Implementasi program dana BOS sudah sesuai / tidak terjadi ketimpangan denganpetunjuk teknis BOS. Dari tiga belas (13) komponen yang ada dalam juknis BOS yang teranggarkan dari dana BOS, ada tiga komponen yang tidak sesuai. komponen tersebut meliputi poin 9,10 dan poin 12 yaitu pembayaran honor guru, pembelian alat multimedia pembelajaran kegiatan yang melebihi ketentuan juknis Bos, dan praktek kerja industri siswa kelas XI yang tidak dialokasikan dari dana BOS melainkan sekolah memungut dana kegiatan tersebut dari peserta didik. Pada poin 10 yaitu pembelian alat multimedia melebihi ketetapan dari JUKNIS BOS dimana seharusnya pembelian komputer dalam 1 tahun hanya 5 komputer tapi dalam kenyataan pembelian komputer dalam 1 tahun 10 buah. Seharusnya jika sekolah membutuhkan lebih dari ketetapan juknis BOS, mereka bisa mengalokasikan dari dana yang diperoleh dari masyarakat (SPP).

Pihak sekolah seharusnya dapat memaksimalkan anggaran yang didapat dari program BOS sehingga dapat menghindari pungutan-pungutan ke peserta didik yang seharusnya bisa dialokasikan dari dana BOS. Dengan demikian sekolah perlu melakukan perbaikan-perbaikan dalam membuat anggaran/mengalokasikan anggarandan melibatkan TIM BOS sekolah. Seperti yang dinyatakan oleh Suryosubroto bahwa biaya penyelenggaraan sekolah itu meliputi: 1) Pengadaan alat atau bahan manajemen;

2) Pengadaan alat atau bahan pelajaran; 3) Penyelengaraan ulangan, evaluasi belajar, kartu pribadi, rapor dan SKHUN; 4) Pengadaan perpustakaan sekolah; dan Prakarya danpelajaran praktek (Suryosubroto, 2004).

Namun beberapa hal yang sudah dilakukan adalah penyelenggaraan ulangan, pengadaan buku perpustakaan, pengembangan perpustakaan, pengelolaan sekolah (ATK), langganan daya dan jasa telah teranggarkan dari dana BOS. Kecuali pada poin-poin tertentu yang masih perlu perbaikan dalam penganggaran dan pembelanjaan. Untuk menghindari hal-hal tersebut di atas maka menurut Nanang Fatah dalam penganggaran diperlukan secara rinci sumber-sumber dana dari mana saja yang akandiprediksi menjadi masukan dan memperkirakan pengeluaran yang bakal terjadi.

Penganggaran memerlukan proses secara bertahap, yaitu :

1. Mengidentifikasi kegiatan yang akan dilaksanakan dalam periode 
anggaran.

2. Mengidentifikasi sumber-sumber yang dinyatakan dalam uang, mesin danmaterial

3. Sumber-sumber dinyatakan dalam bentuk uang, sebab anggaran pada dasarnyapernyataan finansial.

4. Memformulasikan anggaran menurut format yang telah disepakati.

5. Usaha memperoleh persetujuan dari yang berwenang (pengambilan keputusan)dalam tahap ini dilakukan kompromi melalui rapat-rapat untuk mempertimbangkan secara objektif dan subjektif (Fatah, 1998)

Sementara berkaitan dengan penelitian yang dilakukan oleh Ervy melani Lalupanda, pada prinsip pembiayaan pendidikan termasuk pendidikan anak usia dini, yang diperlukan adalah aspek manajemen, yaitu bagaimana pengelola mengimplementasikan program BOS tersebut sehingga tepat sasaran dalam mendukung kegiatan operasional secara efektif dan efisien (Lalupanda, 2019).

Penelitian yang sama dilakukan oleh Erdiani Silele pada SD Inpres 4 Halmahera Barat dengan hasil temuan bahwa dalam Perencanaan, pengalokasian, penggunaan dana BOS tidak sesuai Juknis BOS dan pelaporan dana BOS tidak dilakukan secara transfaran (Silele, Sabijono and Pusung, 2017). Di SMK YPK Kesatuan Jakarta pada tiga komponen tertentu masih terdapat kesenjangan karena tidak sesuai dengan Juknis BOS, artinya dalam pengalokasian dana BOS yang sudah sesuai dengan juknis BOS maka sekolah terus mempertahankan alokasi anggaran tersebut, bagi komponen yang belum sesuai dengan juknis BOS maka sekolah sebaiknya melakukan evaluasi dalam membuat anggaran agar semua kegiatan bisa dibiayai dengan dana BOS untuk menghindari pungutan-pungutan ke siswa.

\section{Manajemen pengelolaan dana BOS yang berkaitan dengan pembuatan RKS danRKAS}

Manajemen pengelolaan program BOS di SMK YPK Kesatuan Jakarata meliputi

a) Pembuatan perencanaan program awal tahun ( RKS dan RKAS) dan analisis kegiatan; b) Pelaksanaan program (Penunjukkan pihak pihak yang terlibat dalam perencanaan; dan c) Pengawasan oleh guru, komite sekolah, kepala sekolah dan Tim BOS. Dalam hal ini di SMK YPK Kesatauan Jakarta tidak memiliki dokumen RKS yang bisa dianalisis oleh peneliti, sekolah melaksanakan kegiatankegiatan rutin selama satu tahun tidak berdasarkan RKS dan RKAS semua berjalan tanpa perencanaan yang baik dan dilakukan secara spontanitas.

Padahal biaya dalam pendidikan meliputi biaya langsung dan biaya tidak langsung, seperti yang dikemukakan oleh Johns, Morphent dan Alexander : "Education 
has both private and social cost, which may be both, direct indirect, direct cost are incurred for tuition fees, books, room and board. In a public school, the majority of these cost of education are embodied in the earnings which are forgone bay all persons of working age, but forgone earnings are also a cost to societ, a reduction in the total productivity of the nation" (Johns, Morphet and Alexander, 1983).

Dari pendapat diatas biaya pendidikan dapat dikategorikan sebagai berikut: (1) Biaya langsung (Direct Cost), yaitu biaya yang dikeluarkan secara langsung untukmembiayai penyelenggaraan pengajaran, penelitian dan pengabdian pada masyrakat, seperti gaji guru, pegawai non edukatif, buku-buku pelajaran dan bahan perlengkapan lainnya; (2) Biaya tidak langsung (Indirect Cost), yaitu meliputi hilangnya pendapatan peserta didik karena sedang mengikuti pendidikan. SMK YPK Kesatuan Jakarta merupakan salah satu sekolah yang mendapatkan dana Biaya operasional sekolah (BOS)dan dana yang diperoleh dari Sumbangan pembinaan pendidikan siswa (SPP). Artinya dalam dalam hal ini pihak sekolah harus membuat anggaran sekolah dengan dana yang diperoleh dari dana BOS dan dana yang diperoleh dari dana sumbangan pembinaan pendidikan (SPP), kerena tidak semua kegiatan sekolah bisa dianggarkan dari danaBOS.

Sementara pembuatan RKAS dan komite dalam permendikbud No. 3 Tahun 2019Pengelolaan dana BOS SMK menggunakan manajemen Berbasis Sekolah yang artinya:

a. BOS Reguler dikelola oleh Sekolah dengan menerapkan manajemen berbasis sekolah (MBS), yang memberikan kebebasan dalam perencanaan, pengelolaan,dan pengawasan program yang disesuaikan dengan kondisi dan kebutuhan Sekolah;

b. penggunaan BOS Reguler hanya untuk kepentingan peningkatan layanan pendidikan dan tidak ada intervensi atau pemotongan dari pihak manapun;

c. pengelolaan BOS Reguler mengikutsertakan guru dan Komite Sekolah; Sekolahbebas membuat anggaran dari dana BOS dan dari SPP yang disesuaikan dengankebutuhan sekolah dan melibatkan pihak-pihak yang bertanggung jawab dalam kegiatan dan membuat anggaran dari dana SPP siswa, dan melibatkan komite sekolah.

Berkaitan dengan penelitian sebelumnya dalam pembuatan RKAS, Halik, Hidayati dan Amin menjelaskan bahwa pengembangan sekolah secara menyeluruh akanmenjadi dasar perencanaan dan penggunaan dana BOS oleh kepala sekolah tertentu, baik pengembangan jangka panjang maupun jangka pendek. Adapun yang dimaksud dengan pengembangan jangka panjang adalah pengembangan sekolah dalam lima tahun ke depan sedangkan pengembangan jangka pendek adalah pengembangan sekolah dalam satu tahun ke depan (Halik, Hidayati and Amin, 2018).

Semestinya sekolah membuat RKAS yang digunakan sebagai acuan dalam 
membiayai kegiatan-kegitan sekolah dalam jangka satu tahun. di SMK YPK Kesatuan Jakarta peneliti tidak mendapatkan dokumen RKAS yang dibuat oleh sekolah pada awaltahun ajaran baru. Kepala sekolah mempunyai peran yang sangat penting dalam mengatur,mengelola keuangan yang dituangkan dalam RKAS.

Dalam hal ini yang memiliki peran penting dalam mengatur manajemen sekolah adalah kepala sekolah seperti yang dikemukan oleh Tim dosen administrasi pendidikan Universitas Pendidikan Indonesia (UPI) bahwa tugas tugas pimpinan itu dirumuskan dalam langkah-langkah pokok organisasi dan manajemen meliputi: (1) Proses perumusan dan perumusan kembali pokok kebijaksanaan secara umum; (2) Proses pemberian, pembagian, dan penggunaan wewenang; (3) Proses pemberian, pembagian, dan penggunaan wewenang; (4) Proses perencanaan; (5) Proses pengorganisasian; (6) Proses penganggaran; (7) Proses kepegawaian; (8) Proses pelaksanaan; (9) Proses pelaporan; dan (10) Proses pengerahan, bimbingan, dan pengendalian (Tim Dosen Adminstrasi Pendidikan Universitas Pendidikan, 2009).

Sementara itu Sulistiyorini memaknai manajemen keuangan dalam arti sempit yang berarti pembukuan. Sementara itu dalam arti luas manajemen keuangan berarti pengurusan dan pertanggung jawaban dalam menggunakan keuangan baik kepada masyarakat, pemerintah daerah, maupun kepada pemerintah pusat, dimulai dari perencanaan, pengorganisasian, pelaksanaan, sampai kepengawasan dan pertanggung jawaban keuangan (Sulistiyorini, 2006).

SMK YPK Kesatuan Jakarta tidak memiliki dokumen RKAS yang semestinya dibuat oleh sekolah pada awal tahun ajaran baru, tapi hal tersebut tidak dilakukan oleh sekolah apalagi membuat rencana jangka menengah (RKJM) untuk kegiatan lima tahun ke depan. Dalam hal ini ini kepala sekolah sebaiknya melakukan evaluasi dan harus melakukan perubahan-perubahan manjemen agar ke depan kepala sekolah bersama Tim manajemen bisa mengelola manajemen keuangan dengan baik dalam perencanaan anggaran, pelibatan Tim dalam perencanaan anggaran dan pembentukan komite sekolahsebagai bentuk pengawasan dan kontrol dalam manjemen penegelolaan keuangan.

\section{PENUTUP}

Program BOS merupakan program yang sangat penting untuk menunjang keberhasilan pendidikan dan kualitas pendidikan dimana semua anak berhak mendapatkan pendidikan yang layak. Oleh karenanya investasi pada modal insani khususnya pada pendidikan anak anak merupakan salah satu cara yang paling efektif dalam meningkatkan kesejahteraan bangsa dalam jangka panjang. Hasil penemuan mendapati bahwa ada beberapa hambatan dalam melaksanakan alokasi dana BOS yang meliputi kurangnya sosialisasi program, lemahnya komunikasi antar pihak yayasan, sekolah dan stakeholder dan ketidakpedulian TIM BOS. Sedangkan padaimplementasinya, dari 13 komponen, ada sepuluh komponen yang sudah sesuai dengan juknisnya. Hal ini menunjukkan bahwa implementasi sudah cukup baik. Dalam hal manajemen pengelolaan, sekolah ini perlu memiliki dokumen dokumen yang diperlukanagar perencanaan berjalan dengan baik. Dalam hal ini kepala sekolah sebagai pemimpin memegang peranan 


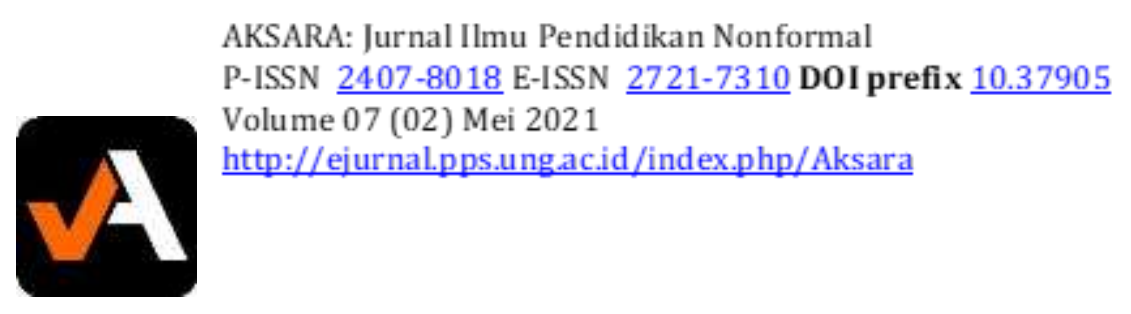

penting dalam mengelola program BOS yang mampu meningkatkan baik performa sekolah maupun peserta didik.

Dari hasil temuan di atas, maka ada beberapa hal yang perlu dilakukan pihak sekolah yaitu pentingnya komunikasi yang efektif antar pihak agar semua program dapat terlaksana dengan baik dan sesuai dengan aturan yang ada. Yang kedua adalah perlunya sosialisasi secara menyeluruh, sistimatis dan terjadwal agar semua pihak dapat memahami program dana BOS yang diberikan pemerintah untuk tercapainya akuntabilitas dan transparansi keuangan. Hal yang ketiga adalah dengan memaksimalkan pengalokasian anggaran dana BOS sehingga dapat memenuhi delapan standard dan komponen komponen yang ada dimana kepala sekolah perlu melakukan analisis kebutuhan sekolah dan penyusunan perencanaan anggaran kegiatan sekolah yang dibantu dengan para wakil serta personilnya.

\section{DAFTAR PUSTAKA}

Anas, A. (2016) 'Implementasi program dana bantuan operasional sekolah SMA Negeri1 Pasangkayu Kabupaten Mamuju Utara', Katalogis, 4(5), pp. 1423.

Anggraini, E. (2013) 'Evaluasi program Bos dalam peningkatan Sarana Pendidikan',

Jurnal Administrasi Pembangunan, 1, pp. 101-218.

Attanasio, O., Fitzsimons, E. and Gomez, A. (2005) The impact of a conditional education subsidy on school enrolment in Colombia. London.

Dearden, L. et al. (2005) Education subsidies and school drop-out rates. WP05/11.

Dearden, L. and Heath, A. (1996) 'Income support and staying in school: What can welearn from Australia's AUSTUDY experiment?', Institute for Fiscal Studies, 17(4), pp.1-30.

Fatah, N. (1998) Studi tentang pembiayaan pendidikan sekolah Dasar. Bandung: PT.Remaja Rosda karya.

Glewwe, P. and Olinto, P. (2004) Evaluating the impact of conditional cash transfers on schooling: An experimental analysis of Honduras's PRAF program. Final Report for USAID. Washington, DC.

Halik, A., Hidayati, N. and Amin, M. (2018) 'Analisis pengelolaan dana bantuan operasional sekolah (BOS) tahun 2017 di SMA Islam Dempo Timur Pasean Pamekasan', e-JRA, 07(08), pp. 96-108. Available at: http://www.riset.unisma.ac.id/index.php/jra/article/viewFile/1447/1419.

Johns, R. L., Morphet, E. L. (Edgar L. and Alexander, K. (1983) The economics andfinancing of education. New Jersey: Prentice-Hall, Inc. Available at: https://www.worldcat.org/title/economics-and-financing-ofeducation/oclc/8476932.

Lalupanda, E. M. (2019) 'Evaluasi implementasi program bantuan operasional penyelenggaraan anak usia dini', Jurnal Manajemen dan Supervisi Pendidikan, 3(2), pp.56-62. doi: 10.17977/um025v3i22019p056.

Maluccio, J. A. and Flores, R. (2005) Impact evaluation of conditional cash transfer.Research Report 141. Washington, DC. 
Oebadillah, S. (2019) 'Penyalahgunaan dana BOS dinilai masih lemah', Media Indonesia, p. 1. Available at: http://mediaindonesia.com/raed/detail/260085- pengelolaan-danabos-dinilai-masih-lemah.

Prihatin, A. A. (2013) Evaluasi program bantuan operasional sekolah (BOS ) danaanggaran pendapatan belanja negara ( APBN ) tahun 2012 ( Studi pada sekolah menengah pertama ( SMP ) Negeri 6 Kabupaten Bintan ). Universitas Maritim Raja Haji. Available at: https://jurnal.umrah.ac.id/wp-content/uploads/2013/08/NasPubAULIA-080563201004-2013.pdf.

Robbin, S. P. (2013) Organizational behavior. New York: Pearson Education. Inc.Prentice Hall.

Schady, N. and Araujo, M. C. (2008) 'Cash transfer, conditions, and school enrollment in Ecuador', Economia Journal, The Latin American and Caribbean Economic Association - LACEA, 0 (spring, pp. 43-77.

Schultz, T. P. (2004) 'School subsidies for the poor: evaluating the Mexican Progresapoverty program', Journal of Development Economics, 74(1), pp. 199-250.

Silele, E., Sabijono, H. and Pusung, R. J. (2017) 'Evaluasi pengelolaan dana bantuan operasional sekolah (BOS) (Studi kasus pada SD Inpres 4 Desa Akediri Kecamatan Jailolo Kabupaten Halmahera Barat) Evaluation of management of operational Funt of case study in The SD Inpres 4 Akediri Village District Jail', Jurnal Emba: Jurnal RisetEkonomi, Manajemen, Bisnis Dan Akuntansi, 5(2), pp. 1626-1635.

Sulistiyorini (2006) Manajemen Pendidikan Islam. Yogyakarta: Elkaf.

Sulistyaningrum, E. (2016) 'Impact evaluation of the school operational assistance program (Bos) using the matching method', Journal of Indonesian Economy and Business, 31(1), pp. 33-62. doi: 10.22146/jieb.10319.

Sunardi (2017) 'Efektivitas penggunaan program bantuan operasional sekolah (BOS) di SMK Kristen Immanuel Kota Pontianak program keahlian akuntansi dengan model evaluasi CIPP (Context, Input, Process, Product )', Jurnal Akuntansi, 2(4), pp. 1-23.

Suryosubroto, B. (2004) Manajemen pendidikan sekolah. Jakarta: Rineka Cipta.

Tim Dosen Adminstrasi Pendidikan Universitas Pendidikan (2009) Manajemenpendidikan. Jakarta: Alfabeta.

Tim Pikiran Rakyat (2019) 'BPK temukan tujuh sekolah Gunakan dana BOS tidak sesuai peruntukan', Pikiran Rakyat, pp. 1-2. Available at: www.pikiran- rakyat.com/pendidikan/pr-01318254/bpk-temukan-tujuhsekolah-gunakan-dana-bos-tidak-sesuai-peruntukan. 